\title{
Profit-Split Method: Time for Countries to Apply A Standardized Approach
}

\author{
by Jeffery M. Kadet, Tommaso Faccio, and Sol Picciotto
}

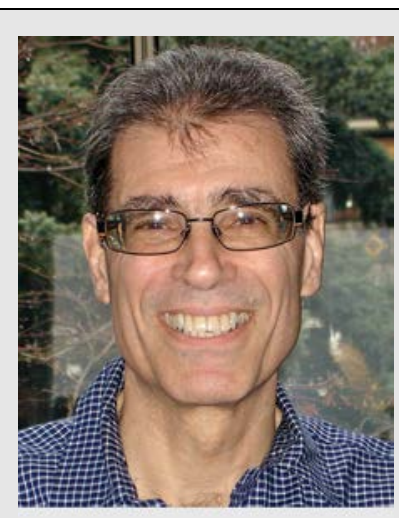

Jeffery M. Kadet

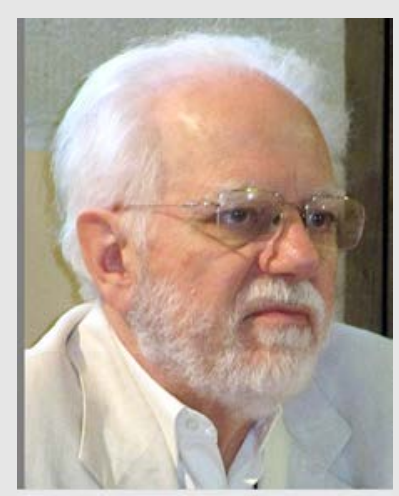

Sol Picciotto

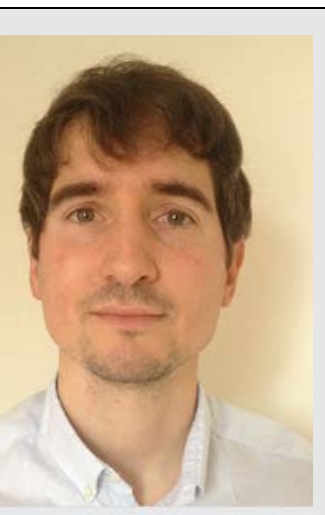

Tommaso Faccio

Jeffery M. Kadet was in private practice for more than 32 years, working in international taxation for several major international accounting firms. He now teaches international tax courses in the LLM program at the University of Washington School of Law in Seattle.

Tommaso Faccio is the head of secretariat of the Independent

Commission for the Reform of International Corporate Taxation (ICRICT) and lecturer in accounting at the Nottingham University Business School in Nottingham, U.K.

Sol Picciotto is emeritus professor of law of Lancaster University; coordinator of the BEPS Monitoring Group (https://bepsmonitoringgroup. org) and senior fellow of the International Centre for Tax and Development, where he conducts research on international tax.

In this article, the authors discuss the future of the profit-split method.

Copyright 2018 Jeffery M. Kadet, Tommaso Faccio, and Sol Picciotto.
Now that the OECD has issued its final guidance on the action 10 profit-split method, ${ }^{1}$ individual countries must determine how they might consider and apply the profit-split method.

It's true that some countries have large and well-staffed transfer pricing audit groups that include economists and other tax professionals knowledgeable in the application of transfer pricing principles and rules. However, those resources are never enough to match the legions of specialists that can be deployed by large multinational groups.

The situation is even worse elsewhere. Most countries not only have significant resource and personnel constraints, but they also simply do not have the internal expertise to effectively apply transfer pricing rules to the multiple industries in which multinational groups operate. For those countries, applying the complex and subjective transfer pricing rules, including analyzing and understanding accurately delineated controlled transactions as contemplated by the OECD transfer pricing guidelines, is simply not an option. ${ }^{2}$

OECD, "Revised Guidance on the Application of the Transactional Profit-Split Method: Inclusive Framework on BEPS: Action 10" (2018).

${ }^{2}$ Paragraph 58 of the revised guidance provides an excellent example of how complex and subjective any application of the guidelines can be. This paragraph provides a "note" that accompanies Example 11. It states, in part:

The example is intended to exemplify in a simple manner the mechanisms of a residual profit split and should not be interpreted as providing general guidance as to how the arm's length principle should apply in identifying arm's length comparables and determining an appropriate split. It is important that the principles that it seeks to illustrate are applied in each case taking into account the specific facts and circumstances of the case. In particular, it should be noted that the allocation of the residual profit may need considerable refinement in practice in order to identify and quantify the appropriate basis for the split. Where R\&D expenditure is used, differences in the types of $R \& D$ conducted may need to be taken into account, e.g. because different types of R\&D may have different levels of risk associated with them, which would lead to different levels of expected returns at arm's length. Relative levels of current $R \& D$ expenditure also may not adequately reflect the contribution to the earning of current profits that is attributable to intangible property developed or acquired in the past. 
There is an important reason why tax authorities in both developing and developed countries will push for wider use of the profitsplit method. A common mechanism in many profit-shifting structures is to allocate to local group members a low routine return, leaving all residual profits in members located in countries where those profits will be subject to zero or low tax. We expect that tax authorities in countries experiencing those tax losses will try to widen the application of the profit-split method, using the OECD's final guidance to identify the method as the most suitable in many circumstances. ${ }^{3}$

That creates a conundrum. On the one hand, through both traditional audit procedures and risk assessments allowed by country-by-country reporting, tax authorities worldwide will identify an increasing number of situations for which the profit-split method is the most appropriate. On the other hand, developing countries, as well as many developed countries, simply do not have the resources to apply transfer pricing methods as contemplated by the guidelines.

An approach to applying the profit-split method that avoids resource-consuming applications under the guidelines, and the required analysis and understanding of every group situation that involves evident transfer pricing risk, is sorely needed. Further, the current ad hoc approach relies on subjective judgments, which creates enormous uncertainty for taxpayers. The approach must be predictable and reduce disputes between taxpayers and tax authorities.

The OECD final guidance represents a consensus that included input from the countries that are members of the inclusive framework on base erosion and profit shifting. The requirement for consensus inevitably means that the guidance can reflect only the lowest common denominator of country positions. Hence, it is unsurprising that the final guidance does not include innovative proposals, such as one from the BEPS Monitoring Group that the OECD and other interested parties should make the profit-split method easy for taxpayers and tax authorities to apply by

\footnotetext{
${ }^{3}$ See Google India Pvt. Ltd. v. Joint Director of Income Tax, combined appeals (ITAT Bangalore 2018)).
}

establishing standardized, concrete allocation keys and weightings for common business models.

The final guidance lists weaknesses of the profit-split method that would be faced in its application, including the need to measure relevant revenue and costs of the applicable group members. As examples, the guidance says applying the profit-split method "could require stating books and records on a common basis and making adjustments in accounting practices and currencies." It goes on to state that "it may be difficult to identify the appropriate operating expenses associated with the transactions and to allocate costs between the transactions and the associated enterprises' other activities." It also points out that identifying appropriate profitsplitting factors could be challenging.

The accounting issues and cost allocations will require work and the application of judgment. But that work and decision-making pales in comparison with the subjectivity and difficulty of accurately delineating controlled transactions, finding relevant comparables, and addressing the almost inevitable ensuing disputes and litigation between taxpayers and authorities.

Further, even in applying other transfer pricing methods, determining relevant revenues and costs must be performed as part of the required functional and other economic analyses. It is surely not too much to hope that the specialists of leading OECD and inclusive framework members could work with the OECD staff to produce helpful guidance that would benefit all.

Also, the weakness of identifying appropriate profit-splitting factors ad hoc will simply fall away when standardized keys and weightings for common business models are applied.

We have suggested that interested parties work together to develop standardized, concrete allocation keys and weightings for common business models. In the absence of jointly developed keys and weightings:

- individual countries or regional groups could develop standardized, concrete keys and weightings to be used for their area's common business models;

- such keys and weightings could be implemented through sectoral advance pricing arrangements developed in 
consultation with relevant industry associations; and

- all such keys and weightings should be made public, which would increase transparency, eliminate the risk of sweetheart tax deals, and encourage other countries and regional groups to adopt them for their common business models.

As examples of common business models, many multinational groups conduct production and sales through global supply chains. Further, many groups earn revenue from internet-based platforms and other digital businesses that supply user access to advertisers and others desiring contact with or information about the users. Other groups, including those with supply chain structures, use software platforms to sell their own and third-party products.

Countries could not only establish standardized, concrete allocation keys and weightings for common business models, but could also require that any groups whose businesses reflect those common business models must use the profit-split method, as well as the approved keys and weightings. Another method or alternative keys and weightings could be used only when a taxpayer establishes to the tax authority's satisfaction that doing so is more appropriate. Hence, this profit-split method approach, including any sectoral APAs, would be on an opt-out basis when the facts and circumstances warrant it.

The suggestion that countries could move to standardize the use of the profit-split method reflects the reality that most multinationals operate under one centrally directed worldwide management. That management coordinates and directs not only the group's overall direction and policies but also the specific day-to-day activities of each member in carrying out the business of the group, which is typically presented as seamless to all third parties (for example, raw material suppliers, vendors, customers, internet platform users, and advertisers). Also, the activities conducted in each location typically represent integral portions of the group's worldwide business that truly add to its earning power and value; they are not independently run local operations that stand on their own.

When a country adopts an approach requiring some common business models to use the profit- split method and the standardized keys and weightings, a taxpayer wanting to use a different method, keys, or weightings would have the burden of proof to show that its choice is in fact more appropriate. Local authorities would have to understand and analyze the accurately delineated controlled transactions only when a taxpayer claimed that another transfer pricing method or other keys and weightings should be used. Equally, taxpayers would be able to rely on the prescribed method, keys, and weightings, which would dispense with the need for a small army of specialists to devise transactional transfer pricing methods and produce the detailed documentation needed to defend them in case of audit.

The approach can be used for both traditional brick-and-mortar and highly digitized business models, because appropriate allocation keys and weightings can be identified to reflect the differences among models. ${ }^{4}$

A prime benefit of adopting this approach is the relative certainty of treatment that taxpayers clamor for. Yes, there will still be some judgment calls and potential audits regarding the applicable revenues and expenses to include in the combined profits that are subject to the profit-split method. However, those decisions and audits will be little different from the many others that all taxpayers and tax authorities face.

When a tax treaty applies such that a mutual agreement procedure might be implemented, using relevant and supportable keys and weightings for a common business model should help focus discussions and resolve competent authority disputes.

Some observers and critics will claim that this standardized approach is too simplistic and does not adequately reflect the differences among groups and how they conduct business. Even so, the fact remains that most countries have neither the resources nor the manpower to apply the complicated and subjective OECD guidelines to

\footnotetext{
${ }^{4}$ For more details about the approach, see prior OECD BEPS Monitoring Group submissions (available at https://

www.bepsmonitoringgroup.org); and Jeffery M. Kadet, "Expansion of the Profit-Split Method: The Wave of the Future," Tax Notes Int'l, Mar. 30, 2015 , p. 1183. Those documents include several examples of concrete allocation keys and weightings as applied to several common business models.
} 
any material portion of the multinationals doing business within their borders.

As the guidelines themselves point out, transfer pricing is not an exact science. Despite this, the guidelines attempt to achieve theoretically correct results in a terribly subjective and complex environment. Seeking those results, however, imposes high costs on taxpayers and impossible burdens on tax authorities. A truly simple approach applied to actual combined profits that provides reasonable results fair to both taxpayers and tax authorities is sorely needed, and a balance between fair results and ease of application must be found.

It is time for individual countries and regional groups to consider adopting that approach. Countries should also consider encouraging the Platform for Collaboration on Tax, made up of the OECD, U.N., World Bank, and IMF, to further develop the approach so that it could more easily be adopted by many countries.

Finally, it is clear that the work on tax consequences of the digital economy centers not only on the definition of taxable presence, but also, and more importantly, on criteria for allocating profit. The G-20/OECD Task Force on the Digital Economy clearly needs to address questions raised about value creation in the digital economy, particularly by users of web platforms. ${ }^{5}$ The increased use of the profit-split method based on standardized allocation keys and weightings for common business models could help ensure that any solutions developed for the tax consequences of digitization do not target a separate sector but can instead be assimilated to strengthen the transfer pricing framework as a whole. ${ }^{6}$

\footnotetext{
See the BEPS Monitoring Group's submission on the tax challenges of digitization proposing a holistic approach that recognizes the value of users in the digital economy. That submission comments, in part:

The main changes due to digitalization are (i) the closer

relationship it both requires and enables between producers and consumers; (ii) the digital services that are often supplied with no direct charge to users, while their inputs are monetised through revenue generated through services provided to other customers, especially advertising; and (iii) the ability that digitalisation gives for some firms to recharacterise themselves as pure intermediaries between producers and consumers.

See in particular the discussion beginning on p. 8 of this submission, which concludes on $p .10$ by stating, "the user base constitutes an asset, although not usually shown in the balance sheet. Hence, it could be taken into consideration in calculating the asset factor if one is used in the formula for allocating profits."

${ }^{6}$ For an in-depth review of the BEPS action 1 history and recent developments concerning taxation of the digital economy, see Monica Gianni, "OECD BEPS (In)Action 1: Factor Presence as a Solution to Tax Issues of the Digital Economy," 72 Tax Law. _ _ (forthcoming 2018). This article includes a proposal for a "factor presence standard" that is conceptually similar to what this article is suggesting for the profit-split method.
} 